Kansas State University Libraries

New Prairie Press

\title{
APPLICATION AND COMPARISON OF THREE SPATIAL STATISTICAL METHODS FOR MAPPING AND ANALYZING SOIL ERODIBILITY
}

George Gertner

Guangxing Wang

Pablo Parysow

Alan Anderson

See next page for additional authors

Follow this and additional works at: https://newprairiepress.org/agstatconference

Part of the Agriculture Commons, and the Applied Statistics Commons

\section{(c) (1) $\Theta$}

This work is licensed under a Creative Commons Attribution-Noncommercial-No Derivative Works 4.0 License.

\section{Recommended Citation}

Gertner, George; Wang, Guangxing; Parysow, Pablo; and Anderson, Alan (2000). "APPLICATION AND COMPARISON OF THREE SPATIAL STATISTICAL METHODS FOR MAPPING AND ANALYZING SOIL ERODIBILITY," Conference on Applied Statistics in Agriculture. https://doi.org/10.4148/2475-7772.1241

This is brought to you for free and open access by the Conferences at New Prairie Press. It has been accepted for inclusion in Conference on Applied Statistics in Agriculture by an authorized administrator of New Prairie Press. For more information, please contact cads@k-state.edu. 
Author Information

George Gertner, Guangxing Wang, Pablo Parysow, and Alan Anderson

This is available at New Prairie Press: https://newprairiepress.org/agstatconference/2000/proceedings/7 


\title{
APPLICATION AND COMPARISON OF THREE SPATIAL STATISTICAL METHODS FOR MAPPING AND ANALYZING SOIL ERODIBILITY
}

\author{
George Gertner*, Guangxing Wang*, Pablo Parysow**, and Alan Anderson*** \\ *NRES, University of Illinois, Urbana, Illinois, USA \\ **School of Forestry, Northern Arizona University, Flagstaff, Arizona,USA \\ ***USACERL, P.O.Box 9005, Champaign, Illinois, USA
}

\begin{abstract}
The Revised Universal Soil Loss Equation (RUSLE) is a model to predict longtime average annual soil loss, related to rainfall-runoff, soil erodibility, slope length and steepness, cover management, and support practice. The soil erodibility factor $\mathrm{K}$ accounts for the influence of soil properties on soil loss during storm events in upland areas.

In this paper, ordinary kriging, sequential Gaussian and indicator simulation methods were used and compared for spatial prediction and uncertainty analysis of soil erodibility based on a data set from a very intensive soil survey ( 524 observations, $10 \mathrm{~m}$ by $10 \mathrm{~m}$ grid). Half the data was used for calibration, the other half used for validation. The results show that the three methods produce similar spatial distributions for predicted values. The method yielding the smallest mean square error was Gaussian simulation, followed by ordinary kriging and indicator simulation. However, the variance estimates obtained using indicator simulation consistent with the spatial variation, while those obtained by Gaussian simulation and ordinary kriging were overly smoothed.
\end{abstract}

Keywords: assessment, prediction, soil erodibility, spatial statistical methods.

\section{Introduction}

Soil erodibility is potentially caused by the integrated effects of rainfall, runoff, and infiltration on soil loss. It is one of six input factors involved in the Revised Universal Soil Loss Equation (RUSLE) to predict longtime average annual soil loss. These six input factors include rainfall-runoff $(\mathrm{R})$, soil erodibility $(\mathrm{K})$, slope length $(\mathrm{L})$ steepness $(\mathrm{S})$, cover management $(\mathrm{C})$, and support practice (P) (Renard et al., 1997). The soil erodibility factor (K) in RUSLE accounts for the influence of soil properties on soil loss during storm events on upland areas as a rate of soil loss per rainfall erosion unit as measured on a given plot unit. The factor depends on soil properties such as silt, sand, organic matter, structure, and permeability. The higher the soil erodibility, the higher the soil loss.

The USDA Natural Resources Conservation Service (NRCS) published soil erodibility factor values for different soil types. $\mathrm{K}$ values are published with a value (class width) whose magnitude indicates the uncertainty associated with that $\mathrm{K}$ value. For example, a $\mathrm{K}$ value of 0.32 with a class width of 0.04 gives a range for that class of $K=.28$ to $K=.36$. For those soils without $\mathrm{K}$ values available, $\mathrm{K}$ values can be estimated using soil erodibility nomographs and data from soil samples (RUSLE, 1995).

Traditionally, spatial prediction of $\mathrm{K}$ values is carried out using a point-in-polygon procedure (Siegel, et al., 1996). A number of field plots with soil samples is first drawn, located and measured. The soil properties of these samples are analyzed in a laboratory and $\mathrm{K}$ values are 
then obtained from published NRCS soil surveys or from soil erodibility nomographs. An average $\mathrm{K}$ value of the field plots for each of the soil type polygons in a soil map is finally calculated and assigned to the cells within the polygon.

The point-in-polygon method is similar to a point-in-stratum method in deriving homogeneous polygons or strata using auxiliary data, such as image data and soil survey data (Wang et al. 1997). Uncertainty for each polygon or stratum is derived using within-polygon or stratum variance, and for a population using a sum of between-polygon or stratum variance and within variances. The difference between the two methods is that the cells in a polygon are spatially joint and the cells in a stratum may not be. Spatially smoothed estimates and variances are the main disadvantage. Besides, the accuracy of product maps depends, to a great extent, on the derivation of homogeneous polygons or strata.

Spatial statistical methods for spatial prediction have been widely used in geology and expanded to applications in natural resource and environmental sciences. For example, Rogowski and Wolf (1994) investigated the variability in soil map unit delineation using kriging interpolation. Mowrer (1997) used a Monte Carlo technique of sequential Gaussian simulation to study propagation of uncertainty through spatial estimation processes for old-growth subalpine forests. Juang and Lee (1998) compared three kriging methods in heavy-metal contaminated soils. Wang et al. (2000) made a comparison of kriging and simulation methods in spatial prediction and uncertainty analysis of topographic factors in RUSLE. These methods are often assessed based on the precision and spatial distribution of estimates and their validation is difficult because of the high cost of obtaining with sufficient resolution.

The objectives of this study are to use and compare three spatial statistical methods for spatial prediction and uncertainty analysis of the soil erodibility factor, $\mathrm{K}$. These methods include ordinary kriging, sequential Gaussian simulation, and sequential indicator simulation. Their assessment is carried out based on overall prediction error, and the spatial distribution and variance of estimates when compared to a validation data set.

\section{Study area and data sets}

The study area is a small section of a large case study area located in Central Texas in Bell and Coryell Counties approximately 160 miles southwest of Dallas, TX. The climate is characterized by long, hot summers and short mild winters (Tazik et al., 1993). Average daily temperature ranges from $8{ }^{\circ} \mathrm{C}$ to $29{ }^{\circ} \mathrm{C}$. Average annual precipitation is $81 \mathrm{~cm}$. Elevations ranges from $180 \mathrm{~m}$ to $375 \mathrm{~m}$ above sea level. Most slopes are in $2 \%$ to $5 \%$ range. Soils are generally shallow to moderately deep and clayey, underlain by limestone bedrock.

At the southwest of the large case study area, 524 soil samples were systematically taken from a $250 \mathrm{~m}$ by $250 \mathrm{~m}$ area. The soil samples were measured at a laboratory for soil properties including silt, sand, organic matter, structure and permeability. The soil erodibility factors (K values) were calculated with the method in Renard et al. (1997, p.74). These samples were systematically divided into two groups by coordinates. Half of the data was used for calibrating the spatial statistical models and for predicting $\mathrm{K}$ values, and the other half of the data was used to validate the methods. 


\section{Methods}

Spatial variability of $\mathrm{K}$ values for the model data set was first determined using semivariograms. Spherical, exponential, Gaussian and power models were entertained for modeling the semivariograms. Ordinary kriging, sequential Gaussian simulation and sequential indicator simulation were then applied to produce prediction and variance maps of $\mathrm{K}$ values. The validation data were used to evaluate the prediction and variance maps. In addition, the predicted maps were compared to that derived by traditional point-in-polygon method from the soil survey.

\section{Semivariogram}

A semivariogram is key to many spatial statistical models and simulation studies because it measures the average dissimilarity between data separated by their physical location. By sampling a continuous variable $\mathrm{Z}$ in a study area, we collect $\mathrm{n}$ observations $\mathrm{z}\left(\mathbf{u}_{\alpha}\right)(\alpha=1,2, \ldots, \mathrm{n})$ where $\mathbf{u}_{\alpha}$ is the vector of spatial coordinates of the $\alpha$ th individual. The semivariogram $\gamma(\mathbf{h})$ is computed as follows:

$$
\gamma(\mathbf{h})=\frac{1}{2 \mathrm{~N}(\mathbf{h})} \sum_{\alpha=1}^{\mathrm{N}(\mathbf{h})}\left[\mathrm{z}\left(\mathbf{u}_{\alpha}\right)-\mathrm{z}\left(\mathbf{u}_{\alpha}+\mathbf{h}\right)\right]^{2},
$$

where $\mathbf{h}$ represents the relative relationship of two locations, called lag, and $N(\mathbf{h})$ is the number of data pairs (Deutsch and Journel, 1998). An experimental semivariogram may be fitted using spherical, exponential, Gaussian and power models. Different directions should be taken into account to determine whether the spatial variability is isotropic or anisotropic.

\section{Ordinary Kriging}

Given $n$ observations $\left\{\mathrm{z}\left(\mathbf{u}_{\alpha}\right), \alpha=1,2,3, \ldots, \mathrm{n}\right\}$ of a continuous variable $\mathrm{Z}$, sampled and measured over a study area, the value of the variable at any non-sampled location $\mathbf{u}$ can be estimated. The ordinary kriging estimator, $Z^{*}{ }_{\mathrm{ok}}(\mathbf{u})$ is (Goovaerts, 1997):

$$
\mathrm{Z}_{\mathrm{ok}}^{*}(\mathbf{u})=\sum_{\alpha=1}^{\mathrm{n}(\mathbf{u})} \lambda_{\alpha}^{\mathrm{ok}}(\mathbf{u}) \mathrm{z}\left(\mathbf{u}_{\alpha}\right) \quad \text { with } \sum_{\alpha=1}^{\mathrm{n}(\mathbf{u})} \lambda_{\alpha}^{\mathrm{ok}}(\mathbf{u})=1,
$$

and where $\lambda_{\alpha}^{\mathrm{ok}}(\mathbf{u})$ is the weight assigned to the datum $\mathrm{z}\left(\mathbf{u}_{\alpha}\right)$, interpreted as a realization of the random variable $\mathrm{Z}\left(\mathbf{u}_{\alpha}\right)$. The variable $\mathrm{n}(\mathbf{u})$ is the number of field data used for the location $\mathbf{u}$ to be estimated and it changes location by location given a neighborhood. For the error variance of the ordinary kriging estimator, refer to Deutsch and Journel (1998) and Goovaerts (1997). Ordinary kriging is unbiased with minimum local error variance and provides a map of the best local estimates, however, this map may not be best as a whole. In addition, the local error variance mainly depends on the data configuration.

Sequential simulation algorithms

Both the Gaussian and indicator simulations methods used for the comparison are based on sequential algorithms. Assume that a study area can be divided into $\mathrm{N}$ nodes of a grid and $\left\{\mathrm{Z}\left(\mathbf{u}_{\mathrm{j}}^{\prime}\right), \mathrm{j}=1,2,3, \ldots, \mathrm{N}\right\}$ is a set of random variables defined at $\mathrm{N}$ locations $\mathbf{u}_{\mathrm{j}}^{\prime}$. A data set $\left\{z\left(\mathbf{u}_{\alpha}\right), \alpha=1,2,3, \ldots, n\right\}$ is sampled. Conditional on this data set, several joint realizations of these $\mathrm{N}$ random variables can be generated:

$$
\left\{z^{(q)}\left(\mathbf{u}_{j}^{\prime}\right), j=1, \ldots, N\right\} \quad q=1, \ldots, L
$$


The key for sequential simulation is that the N-point conditional Cumulative Density Function (cdf) can be expressed as the product of $\mathrm{N}$ one-point conditional Cumulative Density Functions (cdfs) given the set of $\mathrm{n}$ original data values and $\mathrm{N}-1$ realizations (Goovaerts 1997; Deutsch and Journel, 1998). The idea is described in the following:

$$
\begin{array}{r}
\mathrm{F}\left(\mathbf{u}_{1}^{\prime}, \ldots, \mathbf{u}_{\mathrm{N}}^{\prime} ; z_{1}, \ldots, z_{\mathrm{N}} \mid(\mathrm{n})\right)=\mathrm{F}\left(\mathbf{u}_{\mathrm{N}}^{\prime} ; z_{\mathrm{N}} \mid(\mathrm{n}+\mathrm{N}-1)\right) \times \\
\mathrm{F}\left(\mathbf{u}_{\mathrm{N}-1}^{\prime} ; \mathrm{z}_{\mathrm{N}-1} \mid(\mathrm{n}+\mathrm{N}-2)\right) \times \ldots \times \\
\mathrm{F}\left(\mathbf{u}_{2}^{\prime} ; \mathrm{z}_{2} \mid(\mathrm{n}+1)\right) \times \mathrm{F}\left(\mathbf{u} ; \mathrm{z}_{1} \mid(\mathrm{n})\right)
\end{array}
$$

where, for instance, $\mathrm{F}\left(\mathbf{u}_{\mathrm{N}}^{\prime} ; z_{\mathrm{N}} \mid(\mathrm{n}+\mathrm{N}-1)\right)$ is the conditional cdf of $\mathrm{Z}\left(\mathbf{u}_{\mathrm{N}}^{\prime}\right)$ given the set of $\mathrm{n}$ original data values and the $(N-1)$ previous realizations $Z\left(\mathbf{u}_{j}^{\prime}\right)=z^{(q)}\left(\mathbf{u}_{j}^{\prime}\right), j=1, \ldots, N-1$. The simplest case is the joint simulation of $z$ values at two locations $\mathbf{u}_{1}^{\prime}$ and $\mathbf{u}_{2}^{\prime}$. The process of generating realizations $\left\{\mathrm{z}^{(\mathrm{q})}\left(\mathbf{u}_{1}^{\prime}\right), \mathrm{z}^{(\mathrm{q})}\left(\mathbf{u}_{2}^{\prime}\right)\right\}(\mathrm{q}=1, \ldots, \mathrm{L})$ by sampling the two-point conditional cdf can be described with a function that is a product of two one-point conditional cdfs:

$$
\begin{gathered}
\mathrm{F}\left(\mathbf{u}_{1}^{\prime}, \mathbf{u}_{2}^{\prime} ; \mathrm{z}_{1}, \mathrm{z}_{2} \mid(\mathrm{n})\right)=\operatorname{Prob}\left\{\mathrm{Z}\left(\mathbf{u}_{1}^{\prime}\right) \leq \mathrm{z}_{1}, \mathrm{Z}\left(\mathbf{u}_{2}^{\prime}\right) \leq \mathbf{z}_{2} \mid(\mathrm{n})\right\} \\
=\mathrm{F}\left(\mathbf{u}_{2}^{\prime} ; \mathrm{z}_{2} \mid(\mathrm{n}+1)\right) \times \mathrm{F}\left(\mathbf{u}_{1}^{\prime} ; \mathrm{z}_{1} \mid(\mathrm{n})\right)
\end{gathered}
$$

where " $\mid(n)$ " and " $\mid(n+1)$ " denote conditioning the $n$ data values $z\left(\mathbf{u}_{\alpha}\right)$, and on the past realization $\mathrm{Z}\left(\mathbf{u}_{1}^{\prime}\right)=\mathrm{z}^{(\mathrm{q})}\left(\mathbf{u}_{1}^{\prime}\right)$. In practice, the value $\mathrm{z}^{(\mathrm{q})}\left(\mathbf{u}_{1}^{\prime}\right)$ is first drawn from $\mathrm{F}\left(\mathbf{u}_{1}^{\prime} ; \mathrm{z}_{1} \mid(\mathrm{n})\right)$, then the value $z^{(q)}\left(\mathbf{u}_{2}^{\prime}\right)$ is drawn from the conditional cdf at location $\mathbf{u}_{2}^{\prime}$ under the conditional on the realization $z^{(q)}\left(\mathbf{u}_{1}^{\prime}\right)$ in addition to the original data $(n)$.

According to Eq. 4, the following steps can result in a realization of the random vector $\left\{Z\left(\mathbf{u}_{\mathrm{j}}^{\prime}\right), \mathrm{j}=1, \ldots, \mathrm{N}\right\}$.

1) Define a random path for visiting each node of the grid in the study area;

2) At the first location to be visited, model the cdf given the n original data using simple kriging and the modeled semivariograms, and from that conditional cdf, draw a realization which will become a conditional datum for all subsequent drawings;

3) At the $i$ th node visited, model the cdf given the n original data and all (i-1) simulated values at the locations previously visited using simple kriging with the modeled semivariograms, and for the $i$ th node, from that conditional cdf, draw a realization which becomes a conditional datum for all subsequent drawings;

4) Repeat step 3 until all $\mathrm{N}$ nodes are visited and provided with simulated values. Repeat $\mathrm{L}$ times the entire sequential process with different paths to visit the $\mathrm{N}$ nodes, which leads to $\mathrm{L}$ realizations, $\left\{\mathrm{z}^{(\mathrm{q})}\left(\mathbf{u}_{\mathrm{j}}^{\prime}\right), \mathrm{j}=1, \ldots, N\right\}, q=1, \ldots, \mathrm{L}$.

The algorithms for both the sequential Gaussian simulation and sequential indicator simulation are similar. The main difference is that the assumption for Gaussian simulation is that the underlying distribution is Gaussian, while no explicit predefined distribution is assumed for the sequential indicator simulation. Thus, the appropriateness of the Gaussian distribution must be tested before simulation, often calling for a prior transformation of original data into a new data set with a standard normal cdf. The simulated normal score values need to be transformed 
back to the simulated values for the original variable. Moreover, modeling the conditional cdf means determining the parameters (mean and variance) of the Gaussian conditional cdf.

The sequential indicator simulation does not require that an underlying distribution be assumed. However, an indicator transformation is needed. Before simulation, the continuous variable $\mathrm{z}$ is subdivided into $\mathrm{S}+1$ discrete intervals, and $\mathrm{S}$ threshold values $\mathrm{z}_{\mathrm{s}}$ are defined $(\mathrm{s}=$ $1,2, \ldots, S)$. These threshold values are referred to cutoff values. The indicator coding of the measurement data is then carried out as follows:

$$
\mathrm{i}\left(\mathbf{u}_{\alpha} ; \mathrm{z}_{\mathrm{s}}\right)= \begin{cases}1 & \text { if } \quad \mathrm{z}\left(\mathbf{u}_{\alpha}\right) \leq \mathrm{z}_{\mathrm{s}} \quad \mathrm{s}=1, \ldots, \mathrm{S} \\ 0 & \text { otherwise }\end{cases}
$$

The function $F(\mathbf{u} ; z \mid(n))$ is then modeled through a series of $S$ threshold values $z_{s}$ discretizing the range of $\mathrm{z}$ :

$$
\mathrm{F}\left(\mathbf{u} ; \mathrm{z}_{\mathrm{s}} \mid(\mathrm{n})\right)=\operatorname{Prob}\left\{\mathrm{Z}(\mathbf{u}) \leq \mathrm{z}_{\mathrm{s}} \mid(\mathrm{n})\right\} \quad \mathrm{s}=1, \ldots, \mathrm{S}
$$

The $S$ conditional cdf values are interpolated within each class $\left(\mathrm{z}_{\mathrm{s}}, \mathrm{z}_{\mathrm{s}+1}\right]$ and extrapolated beyond the two extreme threshold values $\mathrm{z}_{1}$ and $\mathrm{z}_{\mathrm{s}}$. In addition, modeling the conditional cdf implies determining the $S$ conditional cdf values using one indicator kriging algorithm, which requires indicator semivariograms for all the cutoff values.

Using sequential simulation algorithms can result in a set of realizations providing both a visual measure and a model of spatial uncertainty. If any spatial features, for example, the values of a variable are larger than a threshold value, and occur on most of the L simulated images, the percentage can be used as a measure of uncertainty. For details, refer to Wang (2000).

According to Goovaerts (1997), ordinary kriging estimates are smoothed and are best in local prediction, however, kriging variances depend only on the data configuration and not on the actual observed data, and thus do not adequately reflect uncertainty. Both the indicator kriging and sequential Gaussian methods improve the capability and provide local uncertainty analysis by calculating conditional variances. The conditional variance depends on not only data configuration but also data values. This conditional variance in theory should provide a more realistic assessment of uncertainty across space.

\section{Results}

The location and soil erodibility $\mathrm{K}$ values of the 524 soil samples, and soil types and their $\mathrm{K}$ values from the soil survey are shown in Figure 1. From southwest to northeast, the soil sample $\mathrm{K}$ values increases and the highest values are located at the northeast central area. The study area contains only three soil types, BtC2, DPB and $\mathrm{KrB}$. If the soil types are assigned with published $\mathrm{K}$ values, there are only two values over the area: 0.17 for $\mathrm{BtC} 2$; and 0.32 for both $\mathrm{KrB}$ and $\mathrm{DPB}$. In the resulting $\mathrm{K}$ value map, thus, higher values are mainly located at southwest and lower values at the central area and northeast, the opposite if is inverse with the spatial distribution of the field sampled $\mathrm{K}$ values.

Figure 2 shows a histogram of $\mathrm{K}$ values based on the calibration data.

Four directional experimental semivariograms were calculated and their similarity in structure implies that the spatial variability is isotropic. The parameters and residuals of modeled omni-dimensional experimental semivariograms using spherical, Gaussian, and 
exponential models are listed in the upper part of Table 1. The residuals for each of the models were similar. The best model in terms of fit was the Gaussian, then spherical, and finally exponential. The experimental and modeled Gaussian semivariograms are shown in Figure 3.The estimated nugget, sill variances and maximum distance are respectively, 0.0013, 0.0038 and 117.52. This Gaussian semivariogram was used for ordinary kriging and Gaussian simulation.

The parameters of standardized indicator semivariograms for indicator simulation were derived and are shown in the lower part of Table 1 . The range of soil erodibility $\mathrm{K}$ values was divided into six intervals with five indicator (cutoff) values. When fitting the experimental indicator semivariograms, the spherical model was found to be the best. The nugget variance varies from 0.40 to 0.55 , sill variance from 0.45 to 0.60 , with a range parameter from $80 \mathrm{~m}$ to $160 \mathrm{~m}$. The standardization made the sum of nugget and sill variances equal to 1.0 .

The maximum number of realizations (runs) used for both the Gaussian and indicator simulation methods was 500. The standard deviation of predicted values were plotted against the number of realizations (Figure 4). From 50 to 400 realizations, the standard deviation decreased rapidly, and after 400 realizations the standard deviation stabilized.

Figure 5 shows the predicted images of soil erodibility $\mathrm{K}$ values using the model calibration data set for the three methods. The lowest predicted values occurred in the southwest corner of the area and the highest in the northeast central area. From southwest to northeast, the predicted values increase. The spatial distribution is similar among all the predicted images and appears consistent with that of the data set consisting of the 524 field samples in Figure 1.

In Figure 6, variance images of predicted values using these methods are presented. Ordinary kriging and Gaussian simulation produce smoothed variance images over the entire region. Most of the variances fell in the interval of 0.001 to 0.002 . Indicator simulation give a larger range of prediction variances, and the variances increase from southwest to northeast, which is consistent with spatial distribution of the data sets.

The probability maps for predicted values larger than 0.40 using Gaussian simulation and indicator simulation are given in Figure 7. These maps are very similar in spatial distribution and slight differences exists only at some small areas. These probabilities for the predicted $\mathrm{K}$ values larger than 0.4 increase from southwest to northeast. Most of the probabilities are less than 0.1 at southwest and larger than 0.5 at northwest. These features are supported by the spatial distribution of the data sets in Figure 1.

Additional comparisons were made with the validation data. The three methods are compared in Table 2 based on mean and variance of predictions at the validation points, and mean error and mean square error (error = predicted - observed). Overall, the three methods produce slight overestimation. The Gaussian simulation has the smallest bias and mean square error, then ordinary kriging and finally indicator simulation. However, the errors were not constant. Figure 8 shows the predicted $\mathrm{K}$ values based on the three methods versus the validation $\mathrm{K}$ values. The narrow lines are linear regression lines through the data. It can be seen from this figure that all three methods overestimate when the $\mathrm{K}$ value is small and underestimate when the $\mathrm{K}$ value is large. The methods were assessed in terms of spatial variance. The overall area was systematically divided into $50 \mathrm{~m}$ by $50 \mathrm{~m}$ cells and mean square errors were calculated for each of the cell. Figure 9 shows the mean square error for each method across space. Although the mean square errors are conservative estimates, the mean square errors are not smooth across space like, the variance images of predicted values in Figure 6 for ordinary 
kriging and Gaussian simulation. The spatial distributions of the mean square errors are very similar to the variance images of predicted values based on indicator simulation.

\section{Summary}

Three spatial statistical methods produce similar prediction maps of soil erodibility $\mathrm{K}$ values and the spatial distribution of the predicted values is consistent with that of the model and test data sets, although there was slight overestimation when the $\mathrm{K}$ value is small and underestimation when the $\mathrm{K}$ value is large. Compared to these three spatial methods, the traditional point-in-polygon method results in smoothed spatial prediction and variance maps. At the same time, the use of published soil erodibility $\mathrm{K}$ values from soil surveys may lead to large over- and underestimation compared to the field sample $\mathrm{K}$ values.

According to the mean square error calculated from the test sample $\mathrm{K}$ values and their estimates, suggest that sequential Gaussian simulation is the best method for mapping the soil erodibility factor, then ordinary kriging, and finally sequential indicator simulation. The main reason may be that Gaussian simulation requires normal distribution of data sets and the normal distribution of the model data set used has led to the most suitable use of Gaussian simulation. Theoretically, sequential indicator simulation is very flexible because the distribution of data set need not be predefined. However, unlike Gaussian simulation and ordinary kriging, indicator simulation needs several indicator semivariograms to be developed. The modeling of these indicator semivariograms can be complicated and can lead to additional errors and uncertainty.

Gaussian simulation and ordinary kriging produce only smoothed variance images. For ordinary kriging the reason may be that the error variances depend only on the data configuration. For the Gaussian simulation, the reason may due to two factors, only one semivariogram is used, and that the $\mathrm{k}$ value samples are geographically dense. With indicator simulation, the variance is not based on the configuration of the data.

\section{Acknowledgment}

We are grateful to SERDP (Strategic Environmental Research and Development Program) for providing support for the study and to Mr. Eric Schreiber and Dr. Robert Darmody for collection of field data and laboratory work.

\section{References}

Deutsch, C.V., Journel, A. G., 1998. Geostatistical software library and user's guide. Oxford University Press, Inc.

Goovaerts, P. 1997. Geostatistics for natural resources evaluation. Oxford University Press, Inc.

Juang, K.W., and Lee, D.Y., 1998. A comparison of three kriging methods using auxiliary variables in heavy-metal contaminated soils. J. of Environ. Qual. 27:355-363.

Mowrer, H.T. 1997. Propagating uncertainty through spatial estimation processes for old-growth subalpine forests using sequential Gaussian simulation in GIS. Ecological modelling. 98:7386.

Renard, K.G., Foster, C. R., Weesies, G. A., McCool, D. K., and Yoder, D. C., 1997. Predicting soil erosion*water: A guide to conservation planning with the Revised Universal Soil Loss Equation (RUSLE). U.S. Department of Agriculture, Agriculture Handbook Number 703. Government Printing Office, Washington, I. pp. 1-404. 
Rogowski, A.S., and Wolf, J.K. 1994. Incorporating variability into soil map unit delineations. J. Soil Sci. Soc. Am. 58:163-174.

RUSLE. 1995. User Guide: Revised Universal Soil Loss Equation version 1.04. Soil and Water Conservation Society. pp. 1-145.

Siegel, S.B., Hunt, R.P., Couvillon, C.L., Anderson, A.B., and Sydelko, P. 1996. Evaluation of Land Value Study. Proceedings of the 22nd Environmental Symposium \& Exhibition.

March 18-21, 1996., Orlando FL. Pp. 469-475.

Tazik, D.J., Cornelius, J.D., and Abrahamson, C.A. 1993. Status of the Black-capped Vireo at Fort Hood, Texas, Volume I: Distribution and Abundance. USACERL Technical Report N94/01.

Wang, G., Waite, M.L., and Poso, S. 1997. SMI user's guide for forest inventory and monitoring. University of Helsinki, Department of Forest Resource Management Publications 16. ISBN 951-45-7841-4.

Wang, G., Gertner, G. Z., Parysow, P., Anderson, A. B., 2000. Spatial prediction and uncertainty analysis of topographical factors for the Revised Universal Soil Loss Equation (RUSLE). Journal of Soil and Water Conservation. Third Quarter 2000, p.373-382.

Table 1. Experimental semivariogram models of 262 field sample K values used for modeling.

\begin{tabular}{|c|c|c|c|c|c|c|}
\hline Range & \multicolumn{2}{|c|}{ Sill } & Nugget & \multicolumn{2}{|r|}{ Residual } & Model \\
\hline 233.78 & \multicolumn{2}{|c|}{0.0043} & 0.0007 & & 0.00014 & Spherical* \\
\hline 117.52 & \multicolumn{2}{|c|}{0.0038} & 0.0013 & & 0.00012 & Gaussian \\
\hline 188.87 & \multicolumn{2}{|c|}{0.0065} & 0.0006 & & 0.00019 & Exponential* $^{*}$ \\
\hline \multicolumn{7}{|c|}{ Standardized indicator semivariogram } \\
\hline Indicator & Cutoff $z_{s}$ & Probability & Range & Sill & Nugget & Model \\
\hline 1 & 0.178 & 0.172 & 160 & 0.45 & 0.55 & Spherical \\
\hline 2 & 0.218 & 0.347 & 150 & 0.55 & 0.45 & Spherical \\
\hline 3 & 0.243 & 0.473 & 130 & 0.55 & 0.45 & Spherical \\
\hline 4 & 0.273 & 0.668 & 100 & 0.60 & 0.40 & Spherical \\
\hline 5 & 0.308 & 0.840 & 80 & 0.45 & 0.55 & Spherical \\
\hline
\end{tabular}

* These experimental semivariogram models were not used for modeling $\mathrm{K}$ values.

Table 2. Validation comparison of three spatial methods based on 262 field validation samples.

\begin{tabular}{|c|c|c|c|c|}
\hline Methods & $\begin{array}{c}\text { Mean of } \\
\text { Predictions } \\
\text { (regional) }\end{array}$ & $\begin{array}{c}\text { Variance of } \\
\text { Predictions } \\
\text { (regional) }\end{array}$ & $\begin{array}{c}\text { Mean of difference } \\
\text { (Predicted-observed) }\end{array}$ & $\begin{array}{c}\text { Mean Square Error } \\
\text { (MSE) }\end{array}$ \\
\hline OK & 0.250966 & 0.04929 & 0.001004 & 0.00137 \\
\hline SG & 0.250710 & 0.04741 & 0.000782 & 0.00136 \\
\hline SI & 0.257518 & 0.03902 & 0.008205 & 0.00157 \\
\hline
\end{tabular}



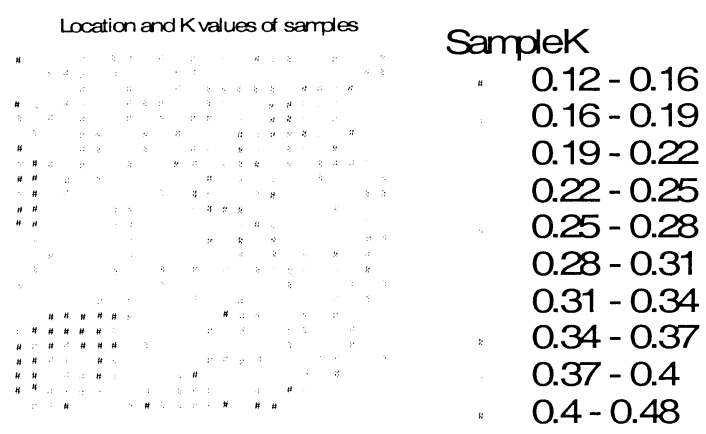

. $0.12-0.16$

$0.16-0.19$

$0.19-0.22$

$0.22-0.25$

$0.25-0.28$

$0.28-0.31$

$0.31-0.34$

$0.34-0.37$

$0.37-0.4$

$0.4-0.48$
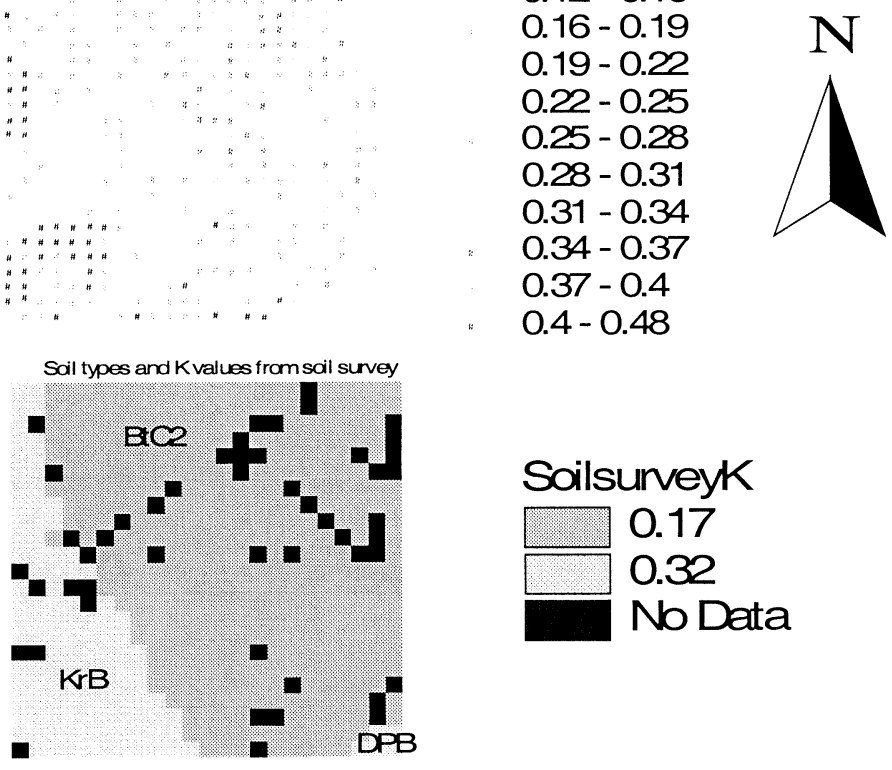

\section{SoilsurveyK}

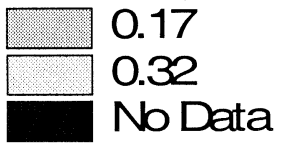

Figure 1. Location and soil erodibility $\mathrm{K}$ values of soil samples (Top), and soil types and $\mathrm{K}$ values from soil survey (Bottom).

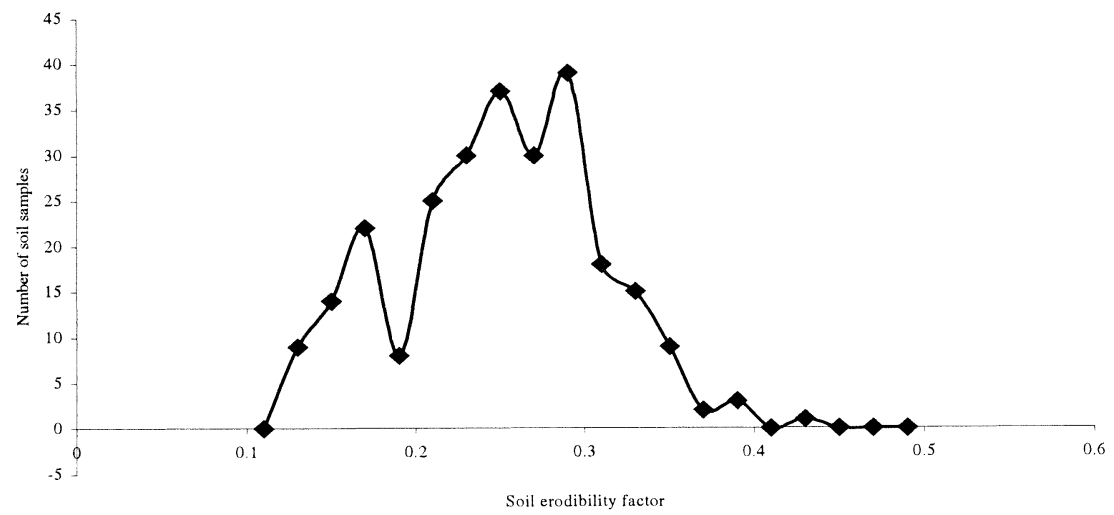

Figure 2. Distribution of soil erodibility factor values 


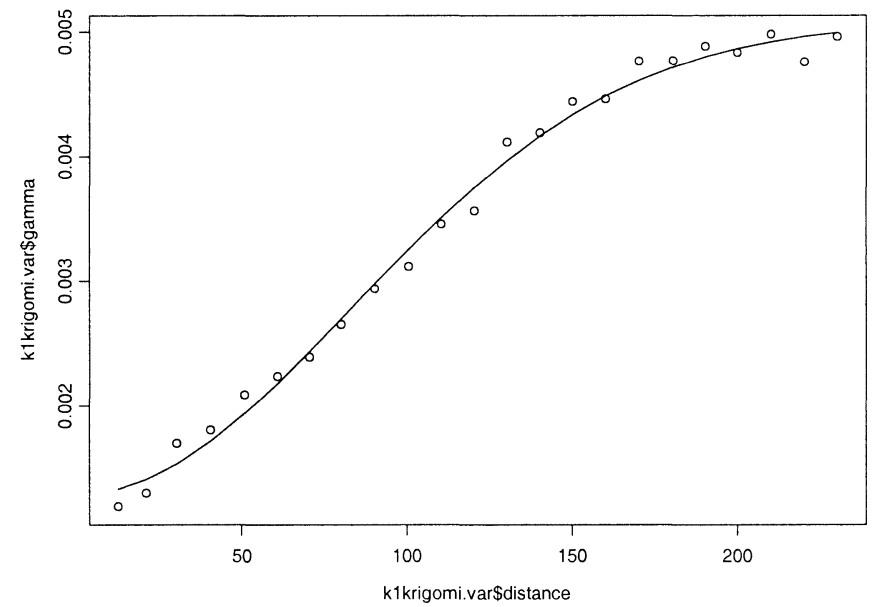

Figure 3. Experimental and modeled omni-dimensional semivariograms of field sample K values for model data set.

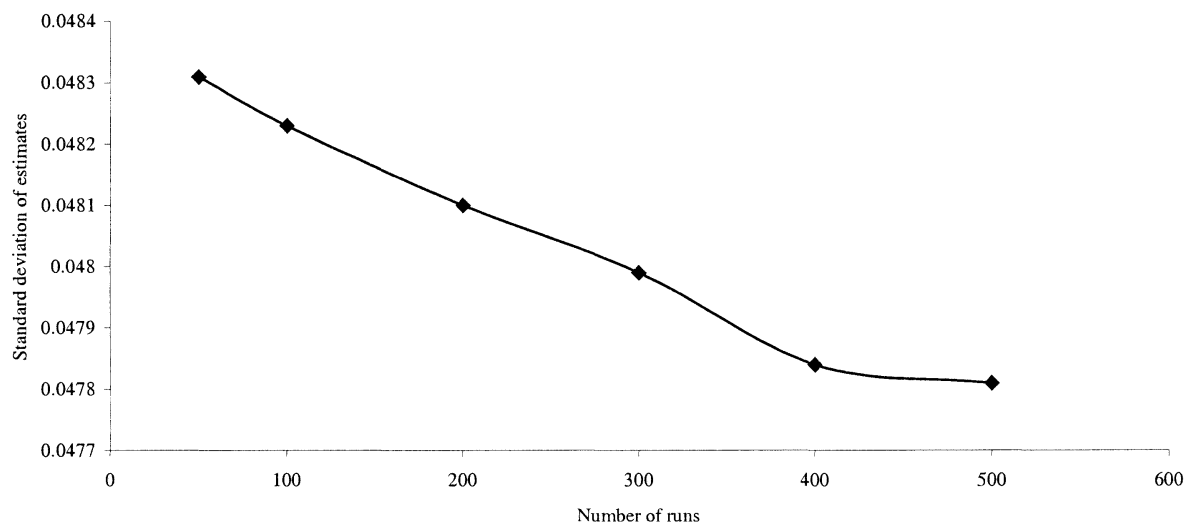

Figure 4. Standard deviation of realizations versus the number of realizations. 

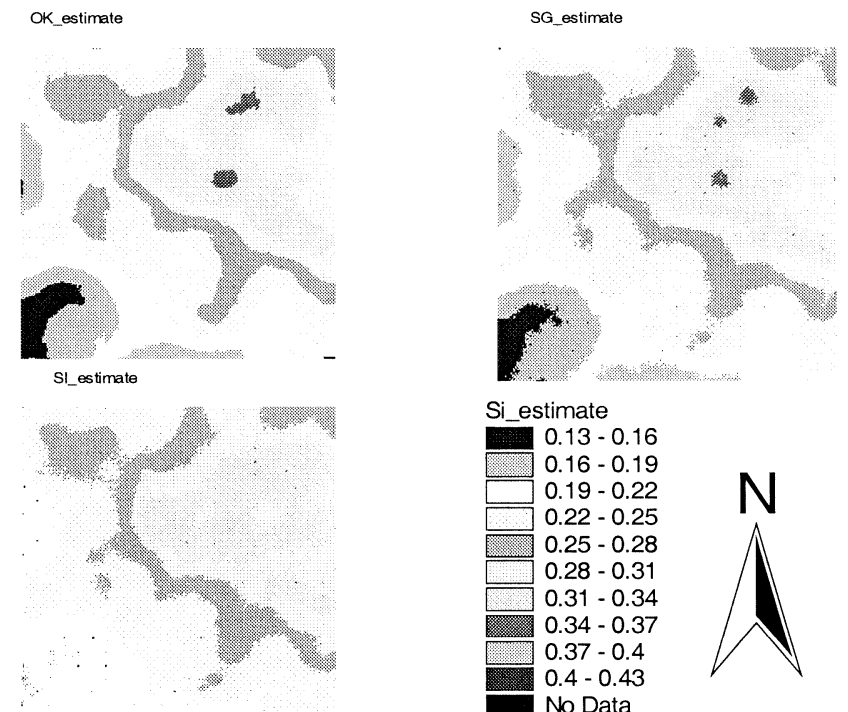

Figure 5. Predicted images of $\mathrm{K}$ factor from model data set using three methods (OK - ordinary kriging, SG - Gaussian simulation, SI - indicator simulation).
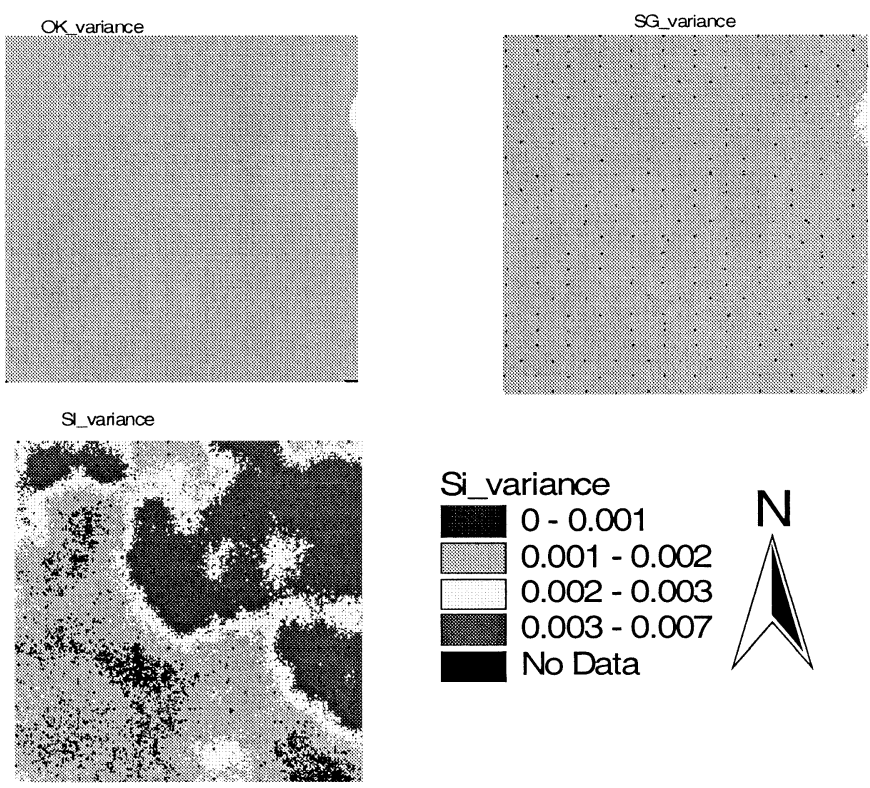

Figure 6. Variance images of predicted $\mathrm{K}$ factor values using the three methods (OK - ordinary kriging, SG - Gaussian simulation, SI - indicator simulation). 

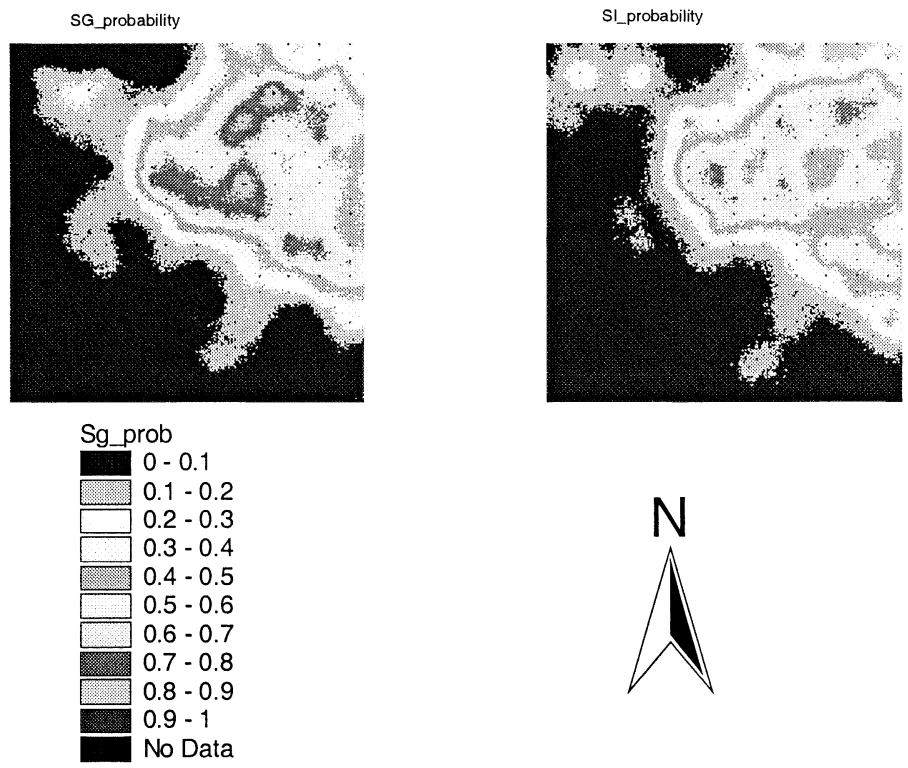

Figure 7. Probability maps for predicted $\mathrm{K}$ factor values larger than 0.40 using Gaussian simulation (SG) and indicator simulation (SI).

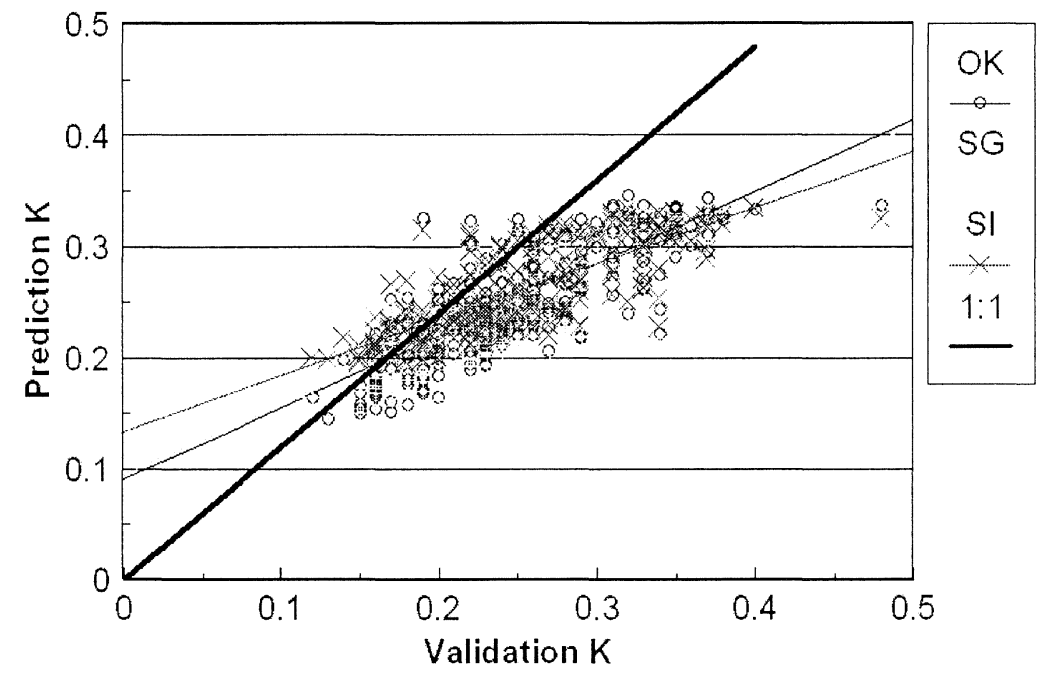

Figure 8. Predicted $\mathrm{K}$ factor versus validation $\mathrm{K}$ factor (OK - ordinary kriging, $\mathrm{SG}$ - Gaussian simulation, SI - indicator simulation). 

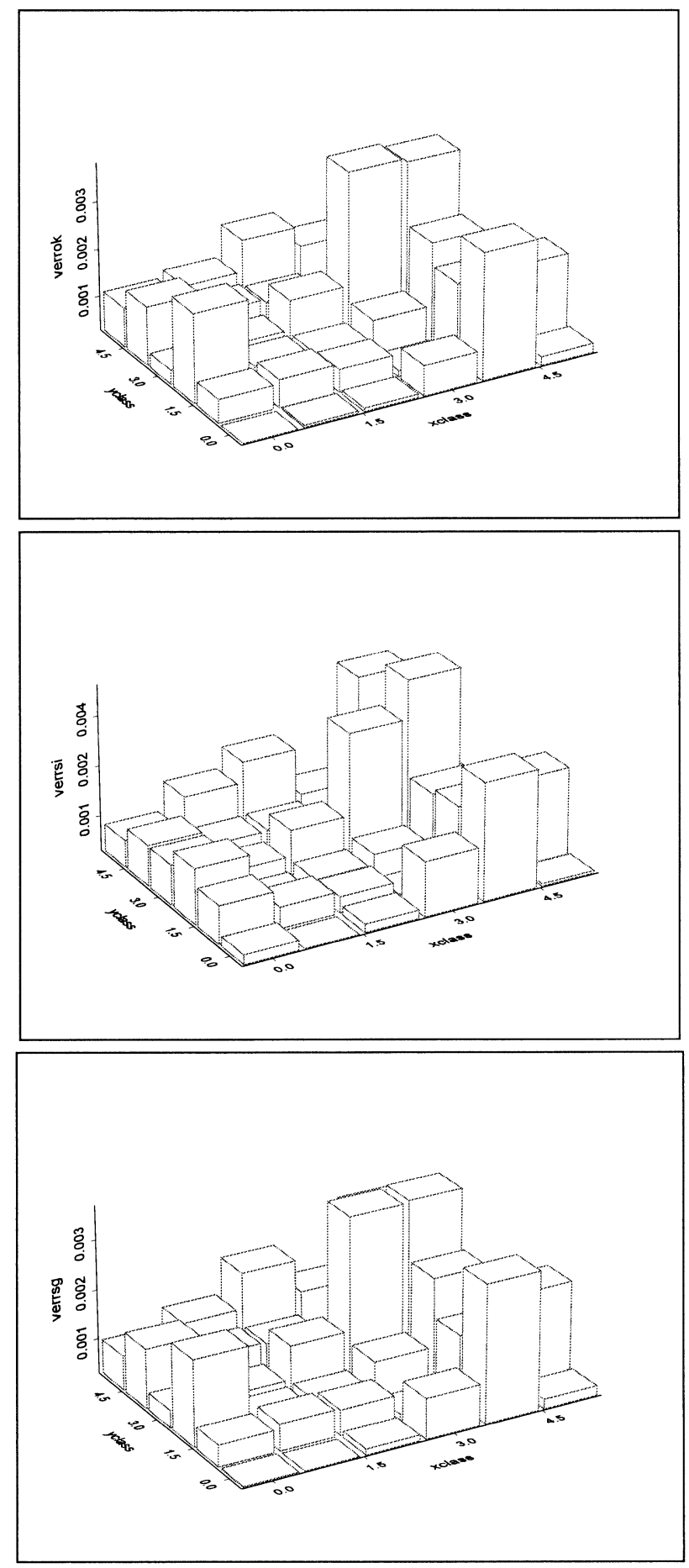

Figure 9. Spatial distributions of mean square of errors within $50 \mathrm{~m}$ by $50 \mathrm{~m}$ cells for ordinary kriging (top), Gaussian simulation (middle) and indicator simulation (bottom). 

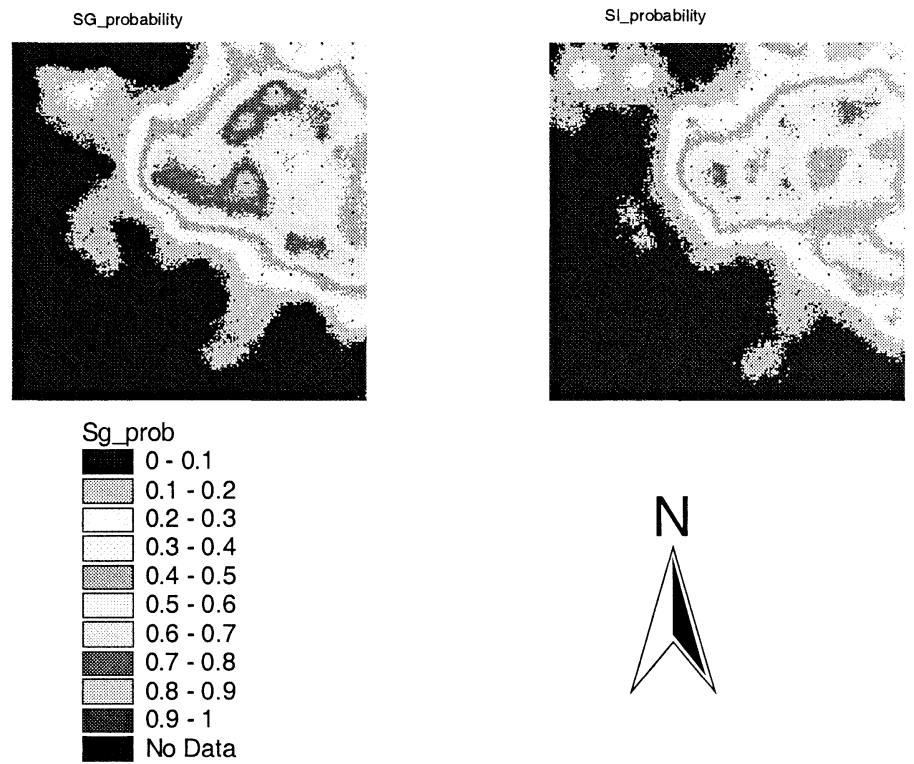

Figure 7. Probability maps for predicted K factor values larger than 0.40 using Gaussian simulation (SG) and indicator simulation (SI).

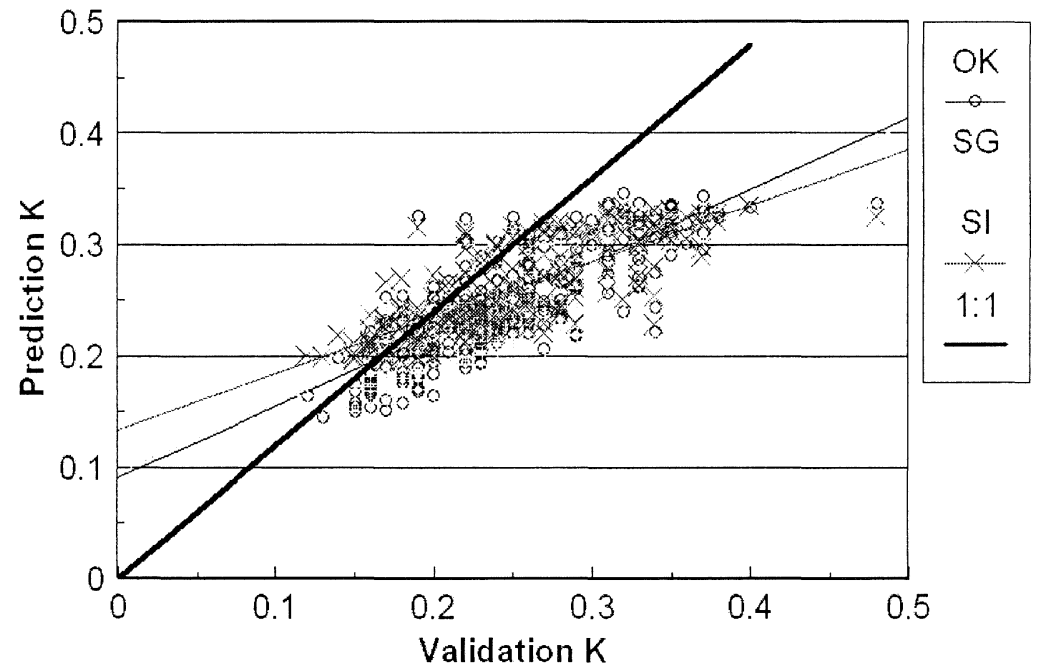

Figure 8. Predicted $\mathrm{K}$ factor versus validation $\mathrm{K}$ factor (OK - ordinary kriging, $\mathrm{SG}$ - Gaussian simulation, SI - indicator simulation). 